em definitivo, o descrédito das preocupações sobre a causalidade social da doença, porém o fato de esses conhecimentos não terem impedido e nem mesmo prevenido o seu espetacular reaparecimento no cenário epidemiológico um século depois 8 mostra que os princípios contidos nos questionamentos ao sistema de saúde levantados nas teses de McKeown, apesar de algumas de suas inconsistências, em sua essência ainda continuam válidos e necessitam ser aprofundados.

Em resumo, podemos dizer que, enquanto a afirmativa de Novaes é extremamente polêmica, se colocada como questão é sem dúvida uma das mais importantes entre aquelas a serem respondidas pelos epidemiologistas que queiram contribuir para o entendimento do nosso sistema de saúde.

1. Global Forum for Health Research. The 10/90 Report on Health Research 2001-2002. Geneva: Global Forum for Health Research; 2002.

2. McKeown T. The role of medicine: dream, mirage or nemesis? Oxford: Basil Blakwell; 1979.

3. Colgrove J. The McKeown thesis: a historical controversy and its enduring influence. Am J Public Health 2002; 92:725-9.

4. Szreter S. The importance of social intervention in Britain's mortality decline c. 1850-1914: a reinterpretation of the role of public health. Soc Hist Med 1988; 1:1-38.

5. Kohn LT, Corrigan JM, Donaldson MS, editors. To err is human: building a safer health system. Washington DC: National Academy Press; 2000.

6. Knobler SL, Lemon SM, Najafi M, Burroughs T, editors. The resistence phenomenon in microbes and infectious diseases vectors: implications for human health and strategies for containment. Washington DC: National Academy Press; 2003.

7. Chernew ME, Hirth RA, Cutler DM. Increased spending on health care: how much can the United States afford? Health Aff (Millwood) 2003; 22:15-25.

8. Barnes DS. Historical perspectives on the etiology of tuberculosis. Microbes Infect 2000; 2:431-40.

\section{Ana Maria Malik Pesquisa em, sobre e para os serviços de saúde: comentários em relação à pesquisa \\ Escola de Administração \\ sobre serviços de saúde no Brasil} de Empresas

de São Paulo, Fundação

Getúlio Vargas,

São Paulo, Brasil.

anamalik@fgvsp.br

O presente comentário tem um viés administrativo, influenciado pelo olhar de uma médica, pesquisadora e orientadora de trabalhos científicos na área de gestão em saúde.

$\mathrm{O}$ artigo de Novaes traz uma abordagem abrangente sobre o movimento de pesquisa em serviços de saúde aplicado à realidade internacional, assumindo a premissa de que há poucas publicações nacionais a respeito. Os serviços de saúde não são, exceto em situações de serviços-escola, objeto familiar à maioria dos docentes, pesquisadores e, mais recentemente (inclusive em face das novas regras dos órgãos avaliadores da pós-graduação no país), dos "publicadores" nacionais.

Observam-se atualmente, na área de serviços de saúde, alguns grandes grupos de atores: técnicos, administradores, consultores, alunos, do segmento tanto de técnicos, quanto de administradores, os usuários e... os pesquisadores. Cada um deles tem seu olhar e seu interesse nos serviços e na área de investigação; esses atores também refletem problemas e características encontrados com freqüência na área de pesquisa em saúde. Por exemplo, há um problema bastante comum quando se olha para os serviços de saúde: os meios para trabalhar de maneira adequada, que afetam técnicos, administradores, usuários e até os pesquisadores. Está-se falando de área física, insumos ou suprimentos, logística e também de diretrizes, protocolos ou desenhos de modelos de assistência.

Nas revistas de área médico-assistencial ou voltadas para saúde coletiva, quase não há publicações sobre gestão de suprimentos ou supply chain, mais freqüentes em textos da área administrativa, raramente direcionados para serviços de saúde. Os artigos, quando aparecem nas revistas da saúde, têm muito mais tom de denúncia ou propaganda que de experimentação de novos modelos de distribuição, situando-se sob a grande denominação de artigos de opinião.

Outro problema comum está relacionado aos modelos de prestação de assistência. Quanto às diretrizes ou protocolos clínicos, há uma série de publicações institucionais na forma de livros (no Brasil os mais conhecidos são da Associação Médica Brasileira, Ministério da Saúde e sociedades de especialistas, bem como de alguns hospitais). Também se observam artigos 
internacionais, em geral sobre como se dão os diferentes processos de implantação 1 .

Alguns desenhos alternativos de modelos internos aos serviços, como os chamados fast tracks e centros de alto volume, já foram objeto de publicação em diversos periódicos internacionais, tanto em revistas médicas de especialidade, quanto nas chamadas revistas médicas "generalistas" tradicionais, ou ainda em algumas revistas voltadas à qualidade de cuidado. No Brasil, esse tipo de experiência vem sendo aplicado em dissertações e teses de pós-graduação de profissionais diretamente ligados à assistência ou às áreas de epidemiologia, saúde pública ou vigilância, que não necessariamente se transformam em artigos e, portanto, acabam ficando mais restritos do que poderiam.

Artigos sobre desenho organizacional em serviços de saúde também são muito raros, constituindo-se basicamente de descrição de modelos existentes, olhando para sua estrutura e raramente para sua função ou seus determinantes. É mais freqüente observar estudos à luz de critérios de organização, esquecendo as especificidades da assistência, provavelmente refletindo a lógica do mundo real.

A opção pelo pragmatismo, ou o primado dos meios sobre os fins, é vista como uma distorção comum em serviços que passam a ser gerenciados mais "profissionalmente". Nesse tipo de cenário, são mais usuais investigações direcionadas para avaliações de desempenho ou construção de cases, encomendadas a consultores ou avaliadores externos. Esses documentos, cujos resultados são análises internas e estratégicas de desempenho, tornam-se relatórios internos ou são usados para ensino de gestão.

Conseqüência desse modelo é a falta de elementos de comparação, apesar da busca constante por benchmarking, chegando-se a usar, à guisa de exemplos ou metas, dados não aplicáveis a sua realidade, ou por não se dar conta disso, ou por se almejar uma realidade diferente, ou simplesmente... faute de mieux. Por falta de hábito de discriminar a qualidade nos trabalhos disponíveis, aceitam-se textos publicados com intenções mercadológicas como relatórios acadêmicos.

No entanto, uma das causas desse problema está na resistência a abrir a porta para a realização de estudos, seja em serviços públicos, seja em privados. Nos Estados Unidos, em revistas indexadas voltadas para a gestão de resultados em hospitais, verifica-se a publicação de algumas experiências vividas pelos gerentes de serviços, como o caso da implementação do Balanced Scorecard (BSC) num hospital universitário 2.
Administradores com formação menos adequada têm dificuldade em formular perguntas a serem respondidas no processo de avaliação e gestão, deixando-as a cargo de consultores que contratam e a quem dão acesso a dados estratégicos. Sendo assim, as informações e os conhecimentos gerados têm utilização e divulgação limitadas. As publicações, quando ocorrem, tendem a ser a louvação de uma experiência ou críticas à formulação do trabalho, uma vez que não se trata de pesquisa com característica científica. As atividades de pesquisa e de consultoria são diferentes, mesmo quando usam o mesmo arsenal metodológico.

A pesquisa em serviços de saúde é usada como instrumento para permitir a estudantes de diferentes cursos aprender sobre a realidade administrativa direcionada a modelos de assistência ou clínica, a fim de tentar complementar a visão teórica da maioria dos programas. Contudo, para alunos de pós-graduação, publicações resultantes de pesquisas, preferencialmente, são obrigatórias. Há calls for papers de congressos colocando como estratégia de recrutamento de trabalhos o fato de serem classificados no Qualis, o que pode aumentar a produção, mas nem sempre a qualidade.

Mecanismos de proteção aos usuários, como os instrumentos de consentimento informado, são justificados em casos de pesquisa clínica ou medicamentosa. Eles não são utilizados de rotina quando se trata de projetos que os submetam a empresas de telemarketing, com as mais diferentes intenções, pois, às vezes, os usuários podem se indispor contra os serviços. Por outro lado, em serviços de saúde e em organizações de ensino, começa-se a exigir esse tipo de documento para entrevistar qualquer pessoa no seu interior, trabalhadores técnicos, gerentes, trazendo com freqüência dificuldades adicionais a quem tenta fazer uma pesquisa.

Será que há alguma pesquisa que mereça ser considerada a mais adequada? Há as mais valorizadas em determinados ambientes, principalmente assumindo a genérica definição de Fulop para investigação em serviços de saúde, já citada no artigo de Novaes: “...tem por objetivo produzir informações confiáveis e válidas... não é uma disciplina científica mas uma área de pesquisa aplicada... adota uma perspectiva populacional..."

Cabe perguntar com que intenção se faz pesquisa nos serviços de saúde no Brasil hoje. Esse questionamento é adequado a qualquer objeto: clínica, gestão, planejamento, pessoas, recursos, usuários, estruturas, qualidade, resultado. Em 2002, na Universidade Estadual de 
Campinas, o autor de uma dissertação de mestrado procurou, nas publicações tradicionais da área, os grupos classificáveis como produtivos, e os resultados encontrados mostraram que a maior parte da produção é perdida, pelo critério de publicação, porque esta produção tem outras finalidade, não sendo preparada e encaminhada para publicação 3 .

Há uma peculiaridade a ser considerada: o interesse daqueles que trabalham nos serviços de saúde, não necessariamente com formação de pesquisadores, mas com intenção de conhecer mais sobre seus serviços ou de divulgálos. Há uma série de eventos nos quais a quantidade de trabalhos apresentados sob a forma de pôsteres ou até de comunicações coordenadas mostra o interesse e a curiosidade desses atores a respeito de novas formas de se relacionar com a realidade. No entanto, às vezes, este pode ser considerado pelos pesquisadores acadêmicos um tipo de trabalho diferente da atividade de investigação. Da mesma forma, pareceristas de revistas científicas, com muita freqüência, não aceitam esses artigos por terem metodologia menos elaborada. Assim, nem eventos, nem publicações de maior circulação. Então, como divulgar a informação produzida nos serviços? Como dela tomar conhecimento?

Por que não conviver com a diferença, numa área ainda tão carente como a investigação em serviços de saúde no Brasil, e estimular todos os grupos interessados a se acercarem mais desta? Isso aumentaria o número de pesquisas, divulgando-as para aqueles que tiverem intenção de interferir na realidade e ampliando o espectro de divulgação para além das mesmas idéias constantemente publicadas.

1. Gross PA, Greenfield S, Cretin S, Ferguson J, Grimshaw J, Grol R, et al. Optimal methods for guideline implementation: conclusions from Leeds Castle meeting. Med Care 2001; 39 (8 Suppl 2):II85-92.

2. Meliones JN, Ballard R, Liekweg R, Burton W. No mission, no margin: it's that simple. J Health Care Finance 2001; 27:21-9.

3. Freire JB. A saúde coletiva acerca-se do hospital: o caso do Hospital Público Regional de Betim [Dissertação de Mestrado]. Campinas: Faculdade de Ciências Médicas, Universidade Estadual de Campinas; 2002.

\section{Suely Rozenfeld}

Escola Nacional de Saúde Pública, Fundação Oswaldo Cruz,

Rio de Janeiro, Brasil. rozenfel@ensp.fiocruz.br
O texto de Novaes, abrangente e com bibliografia farta e atual, vem em boa hora. Os indicadores da produção científica das nossas instituições acadêmicas impressionam em termos de número de programas de pós-graduação, publicações em revistas pertencentes a indexadores de qualidade inquestionável, pesquisadores engajados em instituições acadêmicas internacionais. Mas, a despeito dos avanços, alguns indicadores de desempenho de serviços, e de saúde, impressionam pelo oposto: mortes de bebês em maternidades por infecções controláveis, incidência crescente de certas doenças transmissíveis, como a hanseníase e a tuberculose, filas intermináveis na rede SUS.

Novaes trata de organizar o campo do conhecimento com um olho nos resultados das pesquisas: a atividade investigatória está de fato contribuindo para a melhoria das condições de oferta e de consumo de serviços de saúde? A autora estabelece como marco disciplinar o encontro entre a epidemiologia e a gestão de políticas e de programas, com o aporte da antropologia, da economia e demais áreas. E traz para a reflexão alguns aspectos importantes da atenção à saúde, abrindo espaço para que outros venham à tona. Um deles relaciona-se à expansão da cobertura populacional pelos sistemas de saúde nas décadas de 1970 e 1980, a qual se deu com certo grau de incorporação de tecnologia e resultou em preocupações quanto à capacidade de o processo sustentar-se economicamente.

A essa discussão é preciso agregar, além dos elementos já identificados, a questão da iatrogenia, dos efeitos adversos ocasionados pelo emprego de equipamentos, procedimentos, medicamentos e demais meios diagnósticos e terapêuticos. Afinal, sabe-se que, no campo do uso de tecnologia, vale o aforismo "o dobro de bom não é necessariamente ótimo”. Isso é comprovado pela incidência de $6,7 \%$ de reações adversas graves entre pacientes hospitalizados 1 . Há indícios de que os processos de extensão de cobertura arrastam consigo um elenco de subprodutos danosos: consumo conspícuo, complacência com os interesses dos produtores de equipamentos e insumos, uso de tecnologias testadas inadequadamente, uso insuficiente de protocolos de tratamento. A criação, o fomento e a difusão de linhas de investigação especialmente voltadas para a iatrogenia em suas múltiplas dimensões favoreceriam uma estratégia de mudança do atual modelo de atenção, cujas distorções são amplamente conhecidas.

Outro problema importante é o limite entre as atividades de pesquisa e de regulação (http:// 